\title{
El Genio (1874-1875): La primera revista periódica que insertó fotografías
}

\author{
El Genio (1874-1875): Argazkiak \\ erabili zituen lehenengo aldizkaria
}

\section{El Genio (1874-1875): The first magazine that inserts photographys}

\section{José María Chomón Serna ${ }^{1}$ Miguel Ángel Moreno Gallo²}

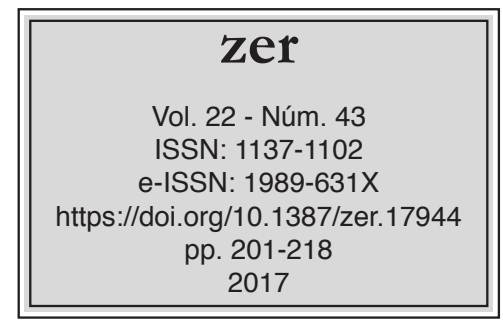

Recibido el 18 de junio de 2017, aceptado el 26 de octubre de 2017.

\section{Resumen}

El Genio fue pionero en el uso de la fotografía como elemento icónico en la prensa. La Diputación Provincial de Burgos conserva un ejemplar del año 1875, en el que se insertan fotografías a la albúmina en ejemplares de tipografía mediante un ingenioso sistema de pegado en espacios en blanco. Aunque hay precedentes de la inserción de páginas con imágenes fotográficas en libros ilustrados, por vez primera los lectores pudieron contemplar testimonios reales icónicos en una revista periódica. El Genio fue obra de la familia Martínez Añibarro.

Palabras clave: Fotografía; prensa; información; siglo XIX; España.

\section{Laburpena}

El Genio izan zen prentsan argazkiak elementu ikoniko gisa erabili zituen lehenengo aldizkaria. Burgosko Foru Aldundiak 1875eko ale bat dauka gordeta; aldizkari hartan, albuminari lehenengo aldiz argazkiak txertatu zitzaizkion tipografia-aleetan, zuriguneen itsaste-sistema burutsu baten bitartez. Aurretik, liburu irudiztatuetan orrialde argazkidunak txertatu izan ziren, baina irakurleek lehenengo aldiz benetako lekukotza ikonikoak ikusi ahal izan zituzten aldizkari batean. El Genio Martínez Añíbarro familiaren obra izan zen.

Gako-hitzak: Argazkilaritza; prentsa; informazioa; XX. mendea; Espainia.

\footnotetext{
Universidad de Burgos, jmchomon@ubu.es

2 Universidad de Burgos, mamgallo@ubu.es
} 


\begin{abstract}
El Genio can be considered a pioneer magazine in the use of photography as an iconic element in the press. The Departmental Library of Burgos (Spain) retains a copy of the magazine El Genio, 1875, in which albumin photographs are inserted in specimens of typography by an ingenious system paste in blanks. There are precedents for inserting pages with photographic images in picture books, but for the first time, readers could watch real testimonies of the life of the Burgos city. El Genio was the work of Martinez Añibarro family.
\end{abstract}

Key words: Photography; newspapers; information; XIX century; Spain. 


\section{Introducción}

El Genio, Revista de Instrucción y Recreo (1874-1875) se adelantó a otras publicaciones periódicas españolas y extranjeras en la inclusión, junto a los textos, de imágenes fotográficas. Puede ser considerada como la primera o una de las primeras publicaciones periódicas españolas que incluyó fotografías.

La historia del periodismo demuestra la necesidad que las publicaciones periódicas tenían de incluir, junto a los textos, elementos icónicos. La fotografía de prensa como tal, es decir, la impresión conjunta de texto e imágenes, no se consiguió hasta 1880 en América, y aún habría que esperar años para reproducir la técnica en España.

Unos años antes de estas primeras experiencias, El Genio, revista periódica publicada en Burgos, incluyó, junto a los textos, dos fotografías. La imposibilidad técnica de unificar en el proceso de impresión los textos y las fotografías se solucionó con un procedimiento singular, consistente en pegar de forma manual las instantáneas en cada uno de los ejemplares. El Genio fue una publicación de la familia Martínez Añibarro, que utilizó también la picaresca para que no apareciera el verdadero director y editor de la misma.

Antes de disponer de la tecnología que permitió la inclusión conjunta de textos y fotografías, las revistas y periódicos publicaron mayoritariamente grabados (Saiz, 1999: 174), en los que se trataban de representar la realidad. La fotografía, frente a los grabados e ilustraciones, tiene como principal ventaja que representa "un fuerte residuo de veracidad y realidad, a modo de certeza notarial de que algo de lo que se muestra ha sido" (Romero, 2012: 154).

Este primer escarceo con la inclusión de elementos iconográficos de carácter fotográfico, en el caso de El Genio, puede ser considerado en el ámbito de lo que Gómez Alonso (2003: 158) señala como "fenómeno estético interno de la publicación que ofrece una identidad corporativa propia".

La prensa periódica en el XIX se caracterizó por su escasa capacidad de gestión empresarial. Los periódicos nacían sin solvencia económica, al albor de la aventura de la aceptación y suscripciones y ello provocó un rosario de aperturas y cierres.

La edición en todo el territorio nacional de un número elevado de publicaciones no debe interpretarse como reflejo de una gran vitalidad, sino todo lo contrario. Se trató de empresas débiles y de iniciativas personales que tenían escasas posibilidades de sobrevivir. Por eso era habitual el cierre y apertura constante de cabeceras. Este afán por editar prensa fue una característica general en todo el territorio español. Esta situación reflejaba en realidad una cierta inmadurez y la inexistencia de un mínimo sector social interesado capaz de garantizar la supervivencia de las empresas periodísticas por la vía de las suscripciones y venta de sus números (Almuiña, 1996: 14).

El Genio formó parte de esta prensa periódica que nació sin solvencia económica. Consecuencia de ello fue se efímera vida. Aunque se desconoce la fecha de su desaparición, es probable que el único número que insertó fotografías fuera también el último. Es decir, sobrevivió menos de un año.

Los periodistas eran personas ilustradas en una sociedad con altos índices de analfabetismo. Y eran, en muchos casos, periodistas de segunda ocupación, que alternaban una profesión principal, con la que sostenían la economía familiar, con su afición por la escritura. En este contexto se enmarca la familia Martínez Añibarro, 
editora de El Genio. La familia Martínez Añibarro se caracterizó por el fracaso de todos sus proyectos periodísticos, lo que no les impidió continuar con otros nuevos. Incluso El Genio fue la historia de un fracaso.

Existieron dos cabeceras con la misma denominación. La primera de ellas, sin vinculación alguna con la que nos ocupa, fue El Genio (1846-1848), órgano de expresión de la Sociedad Artística y Literaria El Genio. Tras su desaparición se convirtió en El Bardo de Castilla (1848-1856). El Genio de esta época fue una revista de periodicidad mensual, a mitad de camino entre la prensa satírica y literaria:

Periódico popular con humos de literario, sin educación, agrio como aceituna sin madurar, de muy malas intenciones y desvergonzado como él solo: publicado por la Sociedad Artística y Literaria de esta Ciudad que lleva el mismo nombre. Gratis para los socios. Este periódico saldrá todos los meses en dos pliegos de marca común y en los días 15 al 20 de cada mes, a empezar desde el próximo febrero. A los señores suscriptores se les insertarán gratis las composiciones que gusten remitirnos, aprobadas que sean por la Junta censura de esta redacción. ${ }^{3}$

Casi 30 años más tarde se editó El Genio (1874-1875), y aunque se trató de la misma denominación, no hay relación entre ambas.

\section{La fotografía en la prensa}

La aparición de imágenes en El Genio es más un rasgo de picaresca creativa que una innovación técnica. Tal vez sea la primera ocasión en que los lectores de una revista salida de una imprenta normal podían ver a la vez texto y fotografías, pero aplicando la original solución de pegar a mano cada albúmina.

La fotografía de prensa como tal, es decir, la impresión conjunta de texto e imágenes, no se consiguió hasta 1880 en América, y aún habría que esperar años para reproducir la técnica en España. Desde la divulgación de la fotografía a mediados del siglo XIX, inmediatamente se intentó insertar esas imágenes en los periódicos, pero las técnicas de impresión de plomo sólo permitían grabados en blanco y negro, sin escala de grises salvo los efectos especiales. Hubo experimentos con huecograbado -las partes más elevadas del grabado no imprimen tinta, sino los huecos que quedan-, fotograbado, fotolitografía, heliograbado, fotogalvanografía, xilografía, dallastipo... Al final todo consistía en proyectar la fotografía sobre una superficie dura y trabajar con un punzón hasta conseguir el mejor molde posible. Pero siempre se trataba de imágenes en blanco y negro, enmascarando los grises mediante el puntillado o el rayado. En algunos casos se consiguieron resultados espectaculares, que cuesta diferenciar de la fotografía directa. En general, es fácil reproducir texturas de elementos inertes, con superficies lisas, pero cuesta plasmar los detalles de la piel humana, el gesto, la verosimilitud en definitiva. Para ello, habría que esperar a una ingeniosa solución que consiste en una trama de puntos de diferente diámetro, un trampantojo que reproduce los blancos con ausencia de puntos, los grises con puntos de diferentes diámetros, y el negro con puntos tan gruesos que son secantes entre ellos.

\footnotetext{
El Boletín Oficial de la Provincia de Burgos incluyó de forma regular anuncios comerciales con la salida de nuevas publicaciones periódicas. En el número 1157 del BOP, del 30 de febrero de 1846, en su página 2, insertó un anuncio dando cuenta de la salida de El Genio de 1846.
} 
Se tiene por cierto que el Daily Herald, de Nueva York, publicó el 4 de marzo de 1880 la primera fotografía, titulada "chabolas", reproducida mediante una técnica de medio tono. Las planchas metálicas con una trama de puntos, que se imprimían a la vez que la tipografía en el papel, pervivieron en la llamada "impresión en caliente" hasta hace apenas unas décadas.

En España, aunque se ha dicho que las primeras fotografías de prensa tienen sus antecedentes en La Ilustración Española y Americana en 1885 (López Mondéjar, 2005: 280), o que la fotografía comenzó a ocupar un lugar importante en las páginas de las revistas en 1895, lo cierto es que se trata de excelentes grabados, obras de artesanía derivadas de fotografías, pero no son imágenes reales, sino la recreación de la mano que mueve el punzón.

El 23 de marzo de 1879, El Globo (Madrid) publicó una imagen de la puerta del baptisterio de San Juan de Florencia que se encuentra a medio camino entre el fotograbado y la fotografía, tal es la perfección. Pero en la revista La Fotografía, de Barcelona, en 1886, ya se advertía que las aplicaciones al grabado de la fotografía eran "industrias muy descuidadas hasta ahora en España" (López Mondéjar, 2005: 28). En la página 99, la revista La Fotografía inserta un excelente fotograbado de Joarizti y Mariezcurrena con una imagen de la Torre d'els Encantats de Caldetas. En 1888, La Ilustración Artística también publicó grabados procedentes de fotografías, aunque se apreciaba aún la falta de definición en las texturas. En 1888, la Ilustración Musical Hispano-Americana publicó retratos de buena calidad, si bien se aprecia en algunos casos el retoque a mano. La Ilustración Ibérica es un tercer ejemplo, ya en 1889, de uso de la fotografía con impresión directa.

Como apunta Pantoja (2007), no es hasta la aparición de revistas como Blanco y Negro, en 1891, y Nuevo Mundo, en 1894, cuando la fotografía se integra definitivamente en la prensa española. Antes de 1900 aparecieron imágenes en las revistas Illustrated American y Paris Moderne y New York Tribune (Wiesenthal, 1979: 218), aunque, como se puede comprobar, para entonces ya estaba generalizada la presencia de las fotografías en la prensa escrita.

Para ver impresa una fotografía de Burgos habrá que esperar hasta el 29 de junio de 1895, cuando Blanco y Negro insertó una panorámica de la plaza Mayor, de Varela Hermanos, durante el entierro de Ruiz Zorrilla. Nuevo Mundo incluyó una foto de Compañy, el 29 de agosto de ese mismo año 1895, de los militares del Regimiento de San Marcial que fueron a Cuba.

Al igual que ocurrió en el resto de España, fue en los inicios del siglo XX cuando los periódicos y semanarios de Burgos comenzaron a insertar fotografías de manera regular. La primera fotografía en un periódico de Burgos apareció en El Castellano el 4 de julio de 1902. Se trataba de un retrato del poeta Antonio de la Cuesta. El Papa Moscas, tras su fusión con Guasa Viva, publicó fotografías en 1917, y Diario de Burgos a partir de 1927.

\section{Metodología}

El hallazgo y puesta en valor del único ejemplar que se conserva de la revista El Genio es producto de una investigación sistemática de la prensa y periodistas del siglo XIX en Burgos. Se ha realizado un inventario cuantitativo de todas las cabeceras conocidas 
y su localización en archivos y bibliotecas provinciales y nacionales. Asimismo, se dispone de una completa relación de periodistas y editores que participaron en estas publicaciones periódicas. Junto a la investigación cuantitativa se ha procedido a una recopilación documental de carácter histórico-cronológico de las noticias, entrevistas y comentarios editoriales que tienen relación con el propio desarrollo del periodismo y su posición frente a otros medios de comunicación y a las autoridades y poderes de cada momento. Producto de esta investigación fue la localización en el Archivo de la Diputación provincial de Burgos del único ejemplar que se ha encontrado de la revista El Genio.

En paralelo se desarrolla otra investigación sobre el periodismo gráfico en Burgos que ha permitido asimismo conocer el entorno profesional y técnico en el que se produjo la primera publicación conocida de fotografías en la prensa del siglo XIX.

La búsqueda de otros ejemplares de esta publicación, o de los números anteriores y siguientes, si es que tuvo continuidad, ha dado lugar a un rastreo sistemático en las bibliotecas locales, provinciales y nacionales; en las hemerotecas conocidas de cualquier ámbito; en los centros educativos y sociales que fueron frecuentados por familia Martínez Añibarro, editores de la revista. También se ha intentado localizar a algún descendiente directo o indirecto de esta familia y se ha recurrido a las empresas y familias de otros editores locales de la época.

Junto a las investigaciones académicas señaladas, se han utilizado, lógicamente, fuentes bibliográficas y documentales -archivos, periódicos del siglo XIX, actas de defunción y nacimiento, revistas y libros científicos- para obtener datos biográficos de la familia editora, su relación con la prensa de la época y su proyección social y académica. A estas mismas fuentes hemerográficas y archivísticas ha sido necesario recurrir para determinar la autoría de las fotografías.

Una vez resuelto el estado de la cuestión, se ha procedido a un análisis morfológico del único ejemplar conservado, tanto de los soportes del texto y de las fotografías como de la tipografía utilizada y las medidas de cajas de impresión, lo que ha permitido conocer el desarrollo técnico e industrial de la imprenta en la que se compuso el ejemplar. A continuación se ha abordado el análisis de los textos y su posible autoría en función de los conocimientos de los diferentes miembros de la familia editora y de la edad de los mismos en el momento de la publicación.

Las imágenes han sido sometidas a un análisis comparativo con otras fotografías y grabados de la época, conservados en la actualidad en archivos y colecciones particulares, lo que ha permitido determinar la autoría y datación temporal, así como el encuadre singular de una de las imágenes y la reutilización años después de algunos elementos decorativos que aparecen en otra fotografía.

Por último, cabe señalar que la Diputación Provincial de Burgos, a la vista del interés de la publicación, ha sometido la misma a un proceso de restauración que permitirá una mejor consulta y, más importante aún, su conservación futura en las mejores condiciones.

\section{El Genio: la autenticidad del editor y director}

El Genio tiene el honor de haber sido la primera publicación periódica de Burgos que incluyó fotografías y puede asegurarse también que, si no fue la primera de España 
-afirmación que siempre es muy difícil de verificar por el gran número de cabeceras desaparecidas o aún no conocidas- sí que fue una de las primeras. Se configura por tanto como una publicación periódica pionera a nivel local y nacional, aunque se desconocen aspectos tan importantes como la identidad de su editor, la fecha de su desaparición o la autoría de algunas de sus láminas.

Se trató de una publicación llena de pequeñas trampas. La primera es la de su fundador y director. Se desconoce con exactitud quién fue, aunque todos los indicios apuntan a José Martínez Rives y posiblemente su hijo Manuel Martínez Añibarro -todos los hijos solían firmar Martínez Añibarro Rives, sin duda para recuperar los apellidos del prestigioso padre-. Sin embargo, figura en la revista como director un joven adolescente de 15 años, Juan, hijo menor de Martínez Rives. La segunda trampa es la referida a las fotografías. Para insertarlas se ideó un método innovador, original y atrevido, como fue el de pegar foto a foto en cada ejemplar. No fue una inserción incluida en el proceso de impresión.

Solo se conserva el Número 12, Año II, del 20 de marzo de 1875. De periodicidad trimensual -salía los días 1, 10 y 20 de cada mes- su primer número se publicó el 1 de diciembre de 1874.

El Genio se definía como "Revista de Instrucción y Recreo". Publicada para ser encuadernada, estaba organizada con una paginación continuada, del tal forma que el único ejemplar que se guarda se inicia en la página 89 y concluye en la 96 . Esta revista era un producto de lujo, por su precio y diseño, orientado a amantes de la lectura y el coleccionismo, con un poder adquisitivo elevado.

El único ejemplar se encontró de forma casual. Fue localizado entre las hojas de un expediente administrativo de la Diputación provincial de Burgos. ¿Cómo llegó allí? Son varias las hipótesis que se pueden establecer. No es descartable que en el Archivo de la Diputación se guardara la colección completa, de la que, finalmente por azar, logró conservarse un solo número. Tampoco es descartable que se trate de un único ejemplar que alguien olvidó entre hojas de expedientes administrativos y que, con el paso de los años, por pura casualidad, pudo ser localizado y puesto en valor.

Una de las principales incógnitas sin resolver es quién fue su editor y director. Sabemos que era un proyecto de la familia de José Martínez Rives, que tuvo tres hijos, José, Manuel y Juan. En la propia publicación aparece como director Juan Martínez Añibarro, que años más tarde sería un reconocido intelectual y militar. Sin embargo, resulta difícil de creer que esto fuera así. Juan Martínez Añibarro nació en Burgos el 11 de marzo de 1859. Cuando se editó la revista, tenía 15 años. Es ciertamente inverosímil que una publicación de tan alta calidad literaria y fotográfica pudiera estar fundada y dirigida por un adolescente.

José Martínez Rives y/o su hijo Manuel parecen las alternativas más probables. Manuel Martínez Añibarro y Rives ocupó un destacado protagonismo como profesor del Instituto de Burgos, director del Museo y archivero de la Biblioteca Provincial. Sin embargo, la figura del padre, José Martínez Rives, es la que reúne mayores posibilidades de ser el autor intelectual de El Genio. Profesor y director del Instituto, director del Museo de Burgos y precursor de un buen número de periódicos en los que trató de publicar la Tercera Parte del Quijote (Tobar, 2009: 337) y la Historia de Burgos. José Martínez Rives fue catedrático de Historia, y este es un dato relevante. El contenido de los artículos firmados por Juan Martínez Añibarro en El Genio revela 
que su autor era un profundo conocedor de la historia y evolución urbanística de Burgos, conocimientos que difícilmente podía tener un adolescente.

Parece difícil que el hermano mayor, José, pudiera estar implicado en el proyecto. Fue un destacado intelectual y científico, pero no se le conocen publicaciones en los periódicos de la época.

Manuel Martínez Añibarro y su padre, por lo tanto, son las opciones más plausibles. Ambos colaboraron en un buen número de publicaciones periódicas y Manuel incluso participó en periódicos que dirigió y fundó su padre. Se trata de los dos miembros de la familia que tuvieron una clara vocación de periodistas y escritores. La revista El Genio tenía su sede en la calle Laín Calvo, 20, que era el domicilio familiar. Lo que desconocemos es la razón última por la que figuraba como director y fundador un adolescente de 15 años.

El Genio se comenzó a publicar en diciembre de 1874 y, casi con toda seguridad, no sobrepasó el año 1875. José Martínez Rives no fundó ni dirigió ninguna publicación periódica entre El Caballero de la Triste Figura (1868) y Fígaro (1879). No es descartable que se tratara de un proyecto en el que prefirió no figurar.

\section{Datos biográficos de la familia Martínez Añibarro}

José Martínez Rives, nació en Madrid en 1820 y falleció en Burgos en 1895, donde fue enterrado, aunque años más tarde sus restos mortales fueron trasladados a Madrid por sus familiares (Ruiz Vélez, 2011: 22). Profesor, periodista, escritor burgalés, obtuvo el título de Licenciado en Filosofía y Letras y Derecho. Catedrático de Historia del Instituto de Logroño y posteriormente del de Burgos, del que llegó a ser director desde el 11 de febrero de 1854 hasta 1864 . También fue presidente de la Comisión provincial de Monumentos de Burgos.

Fundó y participó en múltiples proyectos periodísticos, todos fracasados. Dirigió El Cruzado (1844), Castilla (1844), El Laurel Castellano (1848), El Civilizador (1856), El Eco Burgalés (1861), El Cid (1862), El Caballero de la Triste Figura (1868), y Fígaro (1879). Colaboró, entre otras publicaciones, en El Fomento (1859), El Papa Moscas (1878), El Semanario Pintoresco Español (revista madrileña), El Círculo Moratín (1871), Boletín del Ateneo de Ciencias y Artes de Burgos (1877), Páginas Castellanas (1881), El Heraldo de Castilla (1880), Crónica de Burgos, Ecos de Burgos (1879), La Ilustración de Burgos (1886), y El Sereno (1888).

Manuel Martínez Añibarro nació en Burgos el 3 de septiembre de 1850 -en el censo figura como Manuel María-, en la calle Espolón, n 4, y murió en un tren entre Almería y Alicante el 25 de agosto de 1920. Licenciado en Filosofía y Letras y Derecho, se doctoró en Filosofía y Letras e ingresó por oposición en el Cuerpo de Archiveros, Bibliotecarios y Anticuarios. Desempeñó el cargo de bibliotecario de la Biblioteca Pública de Burgos y conservador del Museo de Burgos, del que llegó a ser su director. Ejerció también como profesor del Instituto de Burgos, y catedrático de Ponferrada, Santander y San Sebastián. Fue miembro de la Real Academia de la Historia y de la de Bellas Artes de San Fernando, de la Comisión Provincial de Monumentos de Burgos y concejal del Ayuntamiento de San Sebastián, entre otros muchos cargos.

Autor de numerosos libros, su obra divulgativa principal fue "Intento de un diccionario biográfico y bibliográfico de autores de la provincia de Burgos", trabajo 
premiado por la Biblioteca Nacional en el concurso público de 1887 e impresa a expensas del Estado. Manuel Martínez colaboró en varios medios de comunicación, aunque con menos intensidad que su padre. Dirigió ocasionalmente El Heraldo de Castilla (1880), y colaboró en otras publicaciones como El Eco del Arlanzón, El Caballero de la Triste Figura (1868), Círculo Moratín (1871), Páginas Castellanas (1881), y El Papa Moscas, (1878).

Juan Martínez Añibarro figura como editor y director de El Genio. Nació en Burgos el 11 de marzo de 1859. Ingresó en la Academia de Artillería de Segovia el 1 de abril de 1876, a los 17 años de edad, donde inició su carrera militar a la que se dedicó hasta su fallecimiento ocurrido en febrero de 1919 en Madrid. No se le conocen relaciones con el periodismo, salvo algunos artículos publicados en el Caput Castellae y en el Boletín de Artillería.

\section{El Genio: estructura y organización}

La revista El Genio consta de dos partes bien diferenciadas: una cubierta de color naranja con letras doradas -todo un exceso tipográfico- y ocho páginas interiores coleccionables. La cubierta tiene unas medidas totales de 23,2 centímetros de alto por 32,1 centímetros de largo. Una vez plegada -de forma desigual en el ejemplar conservado-, se observa que apenas sobresale un milímetro en altura, e incluso en anchura es un poco más estrecha que las páginas interiores.

Las ocho páginas interiores se imprimen sobre dos hojas de 23,0 por 32,4 centímetros, de forma que se obtienen ocho páginas de 23,0 por 16,2 centímetros. La caja de texto (espacio que queda una vez descontados los generosos márgenes de 2,5 centímetros) es de 18,0 centímetros de alto por 11,2 de ancho. Sobre esta caja se imprimen dos columnas de 46 líneas cada una, cifra que puede ser inferior cuando se usa un cuerpo tipográfico de mayor tamaño.

Es precisamente la tipografía uno de los elementos singulares. Evidentemente se trata de composición de caja, sin linotipia -que aún tardaría una década en inventarse y mucho más en llegar a España- lo que supone un laborioso trabajo. Se trata de una familia Romana antigua, idéntica a la utilizada en muchos ejemplares del Boletín Oficial de la Provincia de Burgos, lo que tiene su lógica, porque es en la misma imprenta de Villanueva donde se editó El Genio y donde habitualmente se confeccionaba el periódico oficial. Es una letra muy parecida a la tradicional Ibarra española, pero con algunos rasgos específicos, como el blanco interno de buen tamaño en la e minúscula, el eje vertical de casi todas las letras, serif triangular, esporas planas y barra elevada de la f minúscula.

Se suele utilizar en El Genio el cuerpo 9 interlineado al 11, aunque también hay otras partes (la charada, por ejemplo) del cuerpo 8 sin interlínea, o la entradilla del cuerpo 10, también sin interlinea. La tipografía, aunque a veces parece diferente, es la misma, aunque de otro tamaño y más o menos estrecha.

El ejemplar que se conserva de El Genio es el número 12, de fecha 20 de marzo de 1875 (año II). Indica en la portada que se publica los días 1, 10 y 20 de cada mes, por lo que cabe suponer que comenzó a editarse el 1 de diciembre de 1874, y se desconoce si hubo más números a partir de abril de 1875. La numeración de las páginas del ejemplar número 12 comienza teóricamente en la portada con el 89, si 
bien, como es lógico al figurar la paginación en la parte superior de la revista, no se inserta en dicha portadilla, que se limita a poner el año, la fecha y el número. En la parte superior vemos el título de la revista EL GÉNIO (con acento, fuera de norma ortográfica y muy inusual al tratarse de versales). El lema es "revista de instrucción y recreo".

Se incluyen a continuación los precios de suscripción: 15 reales un trimestre en la capital y 16 reales un trimestre en la provincia, que deberán pagarse en sellos de comunicaciones por adelantado. Los números sueltos se vendían a una peseta. "Los puntos de suscricion [sic] son la Redacción Administración, Laín Calvo 20, donde se dirigirá toda la correspondencia; en la librería de la viuda de Villanueva, Plaza Mayor, y en la de Rodríguez, pasaje de la Flora". El precio era ciertamente elevado para la época, sobre todo si tenemos en cuenta que un periódico diario, como El Globo de Madrid, costaba 6 reales al mes -La Iberia, 8 reales-, apenas cinco céntimos el ejemplar. En algunos anuncios de la época encontramos mantas por 12 reales, botellas de vino de Jerez por 11 reales y el Almanaque Literario e Ilustrado de 110 páginas por 4 reales.

Lo más destacado de la revista es la inserción de las dos imágenes de albúmina. La fotografía horizontal tiene un tamaño de 10,4 por 6,5 centímetros, dentro de un recuadro de 11,0 por 7,3 centímetros, mientras la foto vertical, del mismo tamaño, se inserta en un recuadro de 7,4 por 10,8 centímetros.

Figura 1. Fotografía insertada en El Genio.

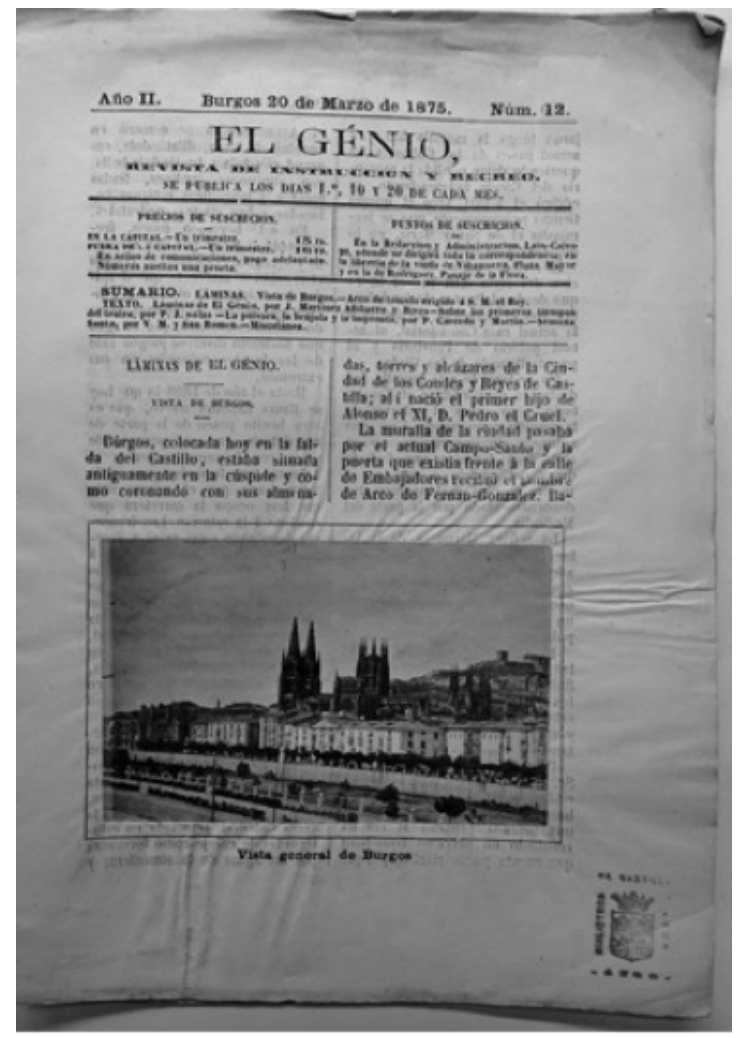


En la primera página se incluye una fotografía general de Burgos. A continuación, las páginas 90,91 y 92 tienen texto, pero no ilustraciones. En la página 93 se incluye la segunda foto, esta vez en vertical, del arco efímero erigido en la futura plaza del Cid con motivo de una visita del Rey. En las páginas 94 y 95 (a esta última le falta el 5) hay únicamente texto, lo mismo que en la 96 y última, donde se insertan, dentro del apartado de miscelánea, una fuga de vocales, una charada, una aclaración, una errata y un pie de imprenta de la viuda de Villanueva.

La aclaración (importante, según se destaca), puede darnos alguna pista sobre las imágenes. Según se informa, "Los señores suscritores [sic] que tengan abonado el presente trimestre y quieran suscribirse al periódico con láminas, tendrán que abonar 6 reales. más del exceso de los dos meses abril y mayo". Cabe suponer, por tanto, que no se incluían con anterioridad fotografías, y que daban por perdida la inversión hecha para este número de finales de marzo. Las fotografías parecen encarecer un real cada ejemplar, cifra significativa, porque la suscripción costaba 15 reales el trimestre -cinco reales al mes, para tres números-, y la suscripción a las fotos casi doblaba el precio inicial. De esta forma, cada ejemplar salía a 67 céntimos, cuando un diario de Madrid podía costar apenas 5 céntimos.

Las dos fotografías que incluye El Genio tienen diferentes características. Una de ellas, la vista general de la ciudad, es divulgativa, intemporal, destinada a agradar a los suscriptores burgaleses. La segunda, aun siendo una vista urbana, tiene un toque de actualidad, casi de reportaje, porque incluye un arco efímero con motivo de la visita real que, como tal, estaba llamado a desaparecer.

La fotografía que incluye $\mathrm{El}$ Genio en la primera página se corresponde con la catalogada con el número 1568 de la colección de Jean Laurent, aunque no está firmada, y fue tomada en esa misma década de 1870. Resulta curioso comprobar que la imagen original (figura 2) ha sido cortada por la parte inferior, cuando precisamente lo que sobra es cielo inerte en la zona superior. Así, desaparece información de la calzada y el muro de la actual calle de Valladolid y se eliminan las dos figuras humanas sentadas junto a un poste (figura 3 ).

Figura 2. Fotografía de Laurent.

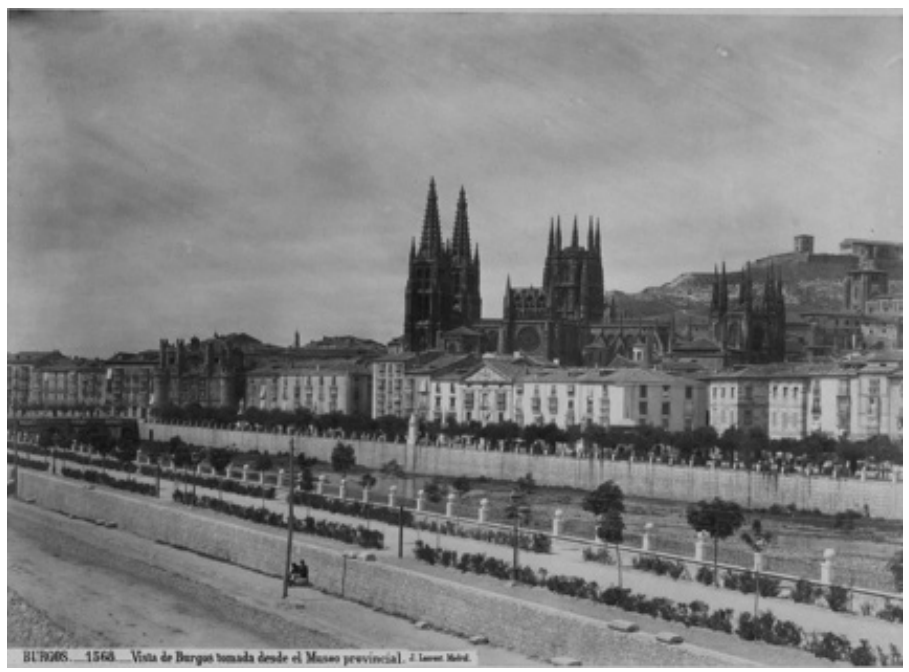


Figura 3. Fotografía insertada por El Genio.

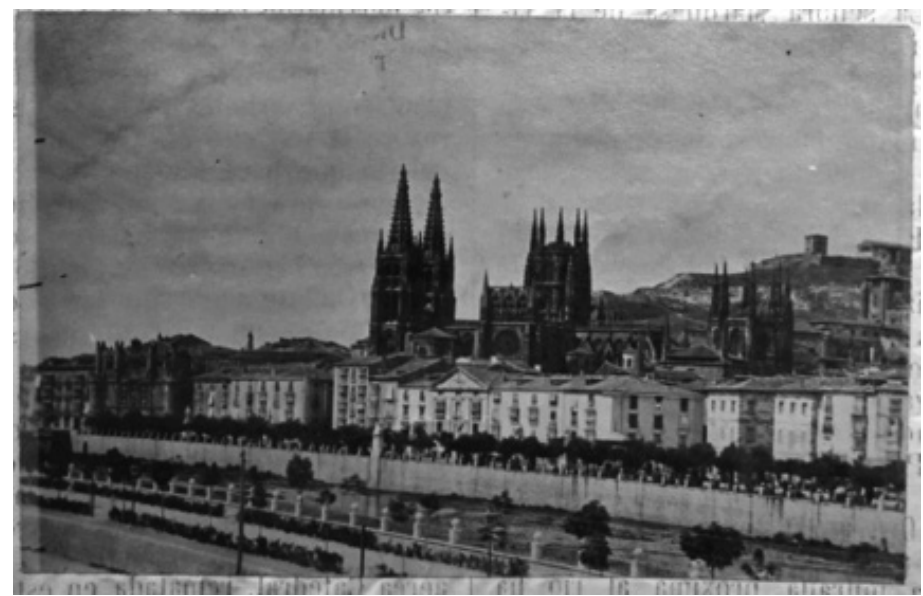

La segunda fotografía, tomada desde el puente de San Pablo, (figura 4) capta el arco efímero construido por el Ayuntamiento para recibir al Rey Alfonso XII el día 10 de febrero de 1875 .

Se desconoce quién pudo ser el autor, aunque los acabados y la coloración de las dos fotos de El Genio parecen similares. Esta imagen no es conocida entre los principales coleccionistas de fotografía antigua. Lo que sí existe (figura 5) es una xilografía publicada en La Ilustración Española y Americana, de 22 de febrero de 1875 (página 124) que reproduce con cierta verosimilitud la escena de la llegada del monarca al centro de la ciudad (Zaparaín y Sainz, 2014: 130).

Figura 4. Fotografía de El Genio.

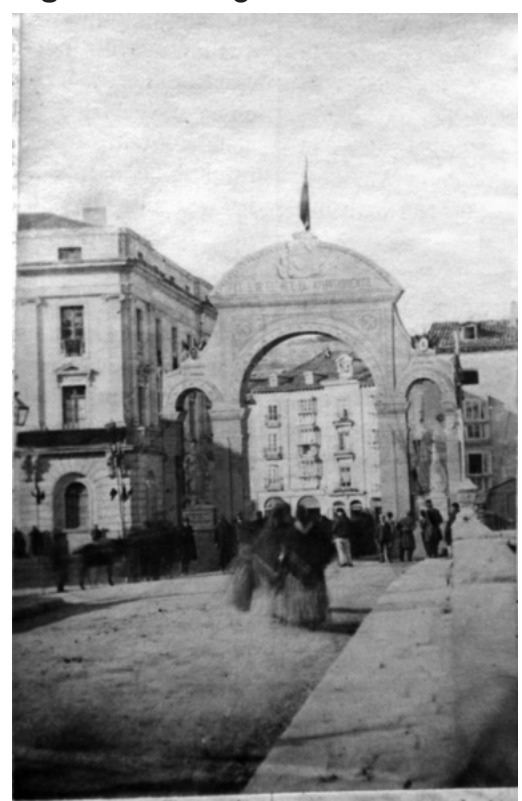


Figura 5. Grabado de La llustración Española de febrero de 1875 (Colección C. Sainz Varona)

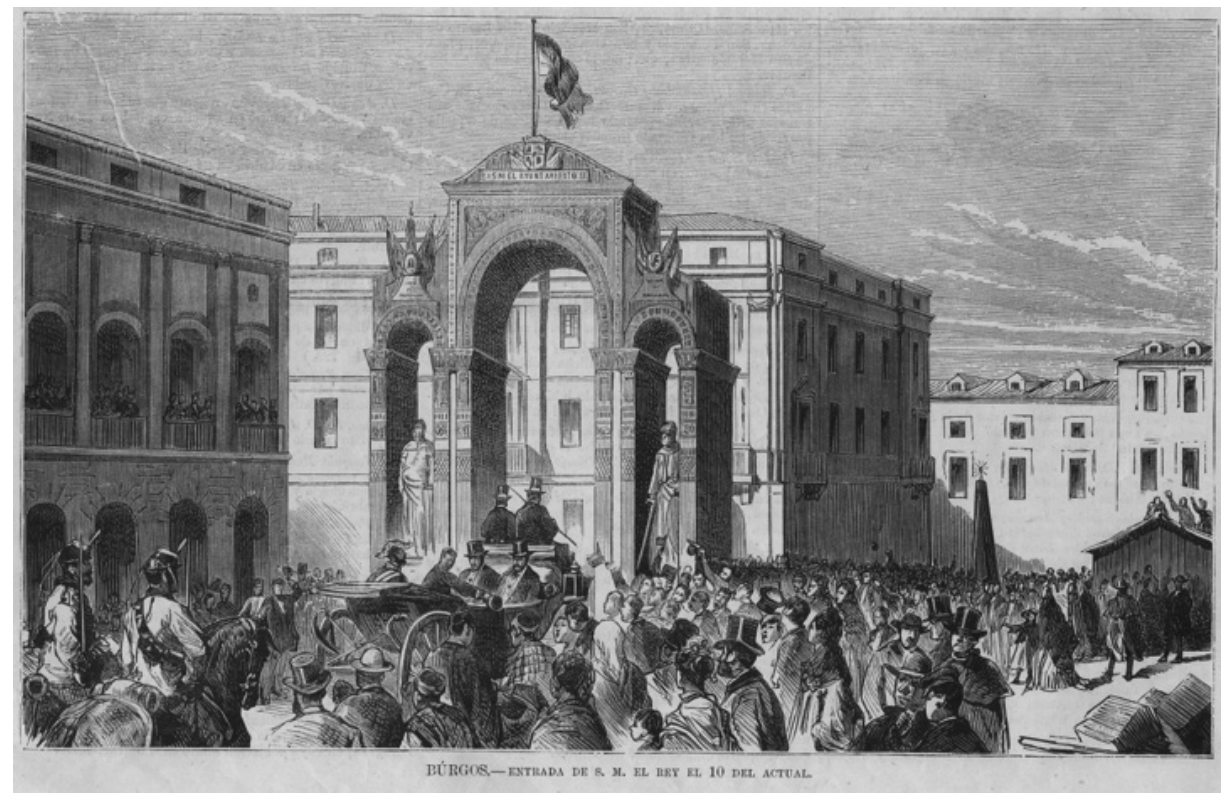

Es curioso comprobar que, 27 años después, el arco efímero de 1875 recogido en la fotografía publicada por El Genio fue de nuevo erigido en el Paseo del Espolón de Burgos con motivo del viaje de Alfonso XIII a la capital castellana en 1902 (Zaparaín y Sainz, 2014: 187).

\section{El Genio: contexto periodístico}

El Genio comenzó a publicarse en 1874, coincidiendo con el inicio de la Restauración. A lo largo del siglo XIX Burgos contó con cerca de 200 cabeceras periodísticas, la mayor parte muy efímeras (Chomón, 2017). De ellas, algo más de 150 se crearon en este periodo, rico en actividad y emprendimiento periodístico, fruto de una legislación más aperturista, como fue la Ley de Policía e Imprenta de 1883, que supuso una auténtica eclosión de publicaciones periódicas en toda España.

La fundación de El Genio se produjo coincidiendo con la aprobación de fuertes restricciones en materia de prensa. El 31 de diciembre de 1874 se suprimieron todos los periódicos no adictos al régimen, aunque poco después se autorizó su reaparición, excepto los republicanos, que quedaron suprimidos. La regulación legal obligaba a que la creación de nuevos periódicos precisaba licencia del Ministerio de la Gobernación. Se exigía, además, un depósito previo de ejemplares con dos horas de antelación antes de la puesta en circulación de los periódicos. En 1875 se creó un Tribunal Especial para delitos de imprenta. Se endurecieron las condiciones económicas para la publicación de periódicos y se estableció la suspensión y censura gubernativa y prohibición de atacar al sistema monárquico. 
El Genio fue una revista dedicada a la cultura, la literatura y la promoción de las riquezas monumentales y naturales de Burgos, por lo que no debió de tener problemas con la legislación restrictiva existente durante su corta vida. La familia de José Martínez Rives destacó por su vocación intelectual ajena a las luchas partidistas. Un ejemplo de ello lo constituye su explicación en el primer número de Fígaro, del 2 de marzo de 1879, de que "no he de hablar de política ni una sola palabra"4.

Cuando El Genio vio la luz, en Burgos se editaban un reducido número de cabeceras periódicas. La Imparcialidad (1784-S. XX); La Voz de los Treinta (18741875); y Ecos del Arlanzón, que salió en 1875. La Imparcialidad era un periódico de maestros, y La Voz de los Treinta y Ecos del Arlanzón, dos publicaciones literarias.

La prensa científica y literaria fue posible por el empeño de personas versadas, con una enorme vocación por escribir, que encontraron en los periódicos y revistas una forma de extender y dar a conocer sus pensamientos y creaciones. Eran intelectuales dedicados a las letras y a las ciencias (Francesc Valls, 1998: 24). De hecho, las primeras publicaciones periódicas fueron literarias y científicas, después vendrían las satíricas, políticas y de noticias. No es extraño comprobar cómo un buen número de escritores se embarcaron una y otra vez en diferentes aventuras, sin que el fracaso de muchas de ellas supusiera un impedimento para comenzar otras. Escribir en un periódico era signo de distinción y prestigio social y fueron muchos los intelectuales que emplearon sus plumas para las columnas periódicas. Las colaboraciones literarias convirtieron a estas publicaciones en una de las principales manifestaciones culturales de la época (Pérez Salas, 2010: 394). En esta línea, El Genio incluyó a un buen número de escritores colaboradores.

\section{Los contenidos}

Esta revista, según el ejemplar que se conserva, dividió sus contenidos en "Vista de Burgos"; “Arco del triunfo erigido á S.M. el Rey”; Láminas de El Genio. Texto por J. Martínez Añibarro y Rives"; "Sobre los primeros tiempos del Teatro", por P. J. Solas; "La pólvora, la brújula y la imprenta", por P. Carcedo y Martín; "Semana Santa", por V. M. y San Román. "Miscelánea"; y "Charada".

En el artículo "Vista de Burgos" se incluye la primera fotografía. El texto es un recorrido histórico de cómo se formó urbanísticamente el paseo más importante de la ciudad: el Espolón. Del mismo se extrae como conclusión que la persona que lo escribió tenía un profundo conocimiento de la historia de la ciudad, ya que aporta datos y detalles históricos y urbanísticos de varios siglos. Este conocimiento es una razón más para resaltar la posibilidad de que el director y editor fuera José María Martínez Rives, profundo conocedor de la Historia de Burgos, que trató de publicar en varios de sus proyectos periodísticos. Este texto ocupa las páginas 89, 90 y 10 líneas en la 91. En esta última se inserta el texto relativo a "Arco de triunfo erigido á S.M. el Rey", al que dedica 22 líneas en la columna izquierda. Sin embargo, no aparece en esta página la fotografía relativa al texto. Lo hace en la 93, seguramente

\footnotetext{
${ }^{4}$ Fígaro fue un periódico literario fundado por José Martínez Rives en 1879. En su primer número del 2 de marzo su fundador y director ratificó la orientación cultural y literaria del semanario. Todos los periódicos y revistas de Martínez Rives coincidieron en su orientación cultural y literaria y su alejamiento de la política.
} 
por una cuestión práctica en la maquetación. Aparece como autor Juan Martínez Añibarro y Rives.

En la página 91 se inserta el artículo "Sobre los primeros tiempos del teatro. La Tragedia y la Comedia. Tespis y Susarion. Primeras noticias", un relato sobre los orígenes de la tragedia y la comedia, que se extiende por las páginas 92 y 93, aunque en esta última el relato rompe su continuidad natural con la inclusión de la fotografía del arco del triunfo relativa al texto insertado en la página 91.

En la página 93 se insertan 5 líneas del inicio del artículo "Semana Santa", que se extiende a las páginas 94 y 95, firmado por V.M. San Román. En esta última página se inicia el artículo "La pólvora, la brújula y la imprenta. Continuación II". Un texto que, según podemos deducir, se inició en la revista número 11 del 10 de marzo de 1875, dedicado a la pólvora; prosiguió en la número 12, donde se dedica a la brújula; y continuó en la número 13, del 1 de abril de 1875 (si es que se editó), con la parte relativa a la imprenta. Este artículo de P. Carcedo y Martín ocupa hasta la columna izquierda de la página 96, que es la última del número 12 que se conserva. En la columna derecha se incluye la sección de "Miscelánea", y una "Charada".

En la portada, en letras doradas, se dice que El Genio es un "Periódico destinado a los intereses generales de la nación, en lo que hace de la Ciencia y el Arte, y a los particulares de la provincia. Publicación ilustrada con fotografías únicas en su clase". En la contraportada se precisan sus objetivos:

Publica especialmente los monumentos naturales y las obras de arte, que constituyeron un verdadero Museo en Burgos, ciudad arqueológica por excelencia. Uno de los objetivos principales de esta publicación es dar a conocer la riqueza tópica de esta parte de Castilla, en lo tocante a las Ciencias Naturales, los adelantos de los Establecimientos y Corporaciones y las costumbres de este suelo clásico de España, mucho más elevado en la escala de la civilización que lo que se juzga generalmente. Creemos que el público estimará nuestros sacrificios.

\section{El método artesanal ideado para la inserción de fotografías}

La revista El Genio insertó fotografías, aunque de un modo muy artesanal, y no como consecuencia de un avance tecnológico que hiciera posible integrarlas en el proceso de impresión. Ante la falta de tecnología se optó por un sistema artesano dividido en varias fases. Podríamos afirmar que la imaginación sustituyó la falta de tecnología.

La primera fase era su maquetación, en la que debía tenerse en cuenta los espacios señalados con un recuadro perfectamente visible en los que posteriormente se integrarían las imágenes fotográficas. La segunda consistía en realizar la impresión de la revista con los textos de los artículos. La tercera era obtener las fotografías a un tamaño idéntico al del espacio asignado para su pegado. Estas fotografías eran aportadas por fotógrafos de la época, tal y como se acredita con la autoría de la instantánea de la panorámica de la catedral. Para ello la familia Martínez Añibarro y Rives debía adquirir a sus autores tantas copias como número de ejemplares impresos. Llama la atención que no se especifique la autoría de las fotografías, y que se las atribuya El Genio. La cuarta parte del proceso consistía en pegar manualmente cada fotografía en el espacio asignado para ello. 
Como puede comprobarse, se trataba de un procedimiento rudimentario, que indudablemente encarecía el coste final, de ahí el alto precio de venta por ejemplar, lo que convertía a esta publicación en un objeto de lujo para coleccionistas.

Mediante este sistema, ingenioso y propio para tiradas no muy elevadas, El Genio se convirtió en la primera publicación periódica de Burgos y posiblemente de España en comercializar una revista periódica con fotografías.

Tras la desaparición de El Genio, en Burgos se tardaron varios años en conocer nuevas publicaciones con fotografías. Cuatro años más tarde de que lo hiciera $E l G e$ nio se publicó Burgos Monumental (1778-1880), un proyecto del fotógrafo burgalés Inclán, que incluyó fotografías de monumentos y edificios emblemáticos de la ciudad. Aunque no han llegado ejemplares conocidos hasta nuestros días, una referencia publicada en el periódico Caput Castellae y recogida por Domingo Hergueta (1929: 189) indica que se trató de un catálogo o cuaderno:

Hemos recibido el primer cuaderno de la revista ilustrada con fotografías que con el nombre de Burgos Monumental ha comenzado a publicarse en esta capital. En dicho número hemos admirado una preciosa vista de nuestra soberbia Catedral hecha por el conocido fotógrafo Sr. Inclán.

Unos años más tarde, en 1886, La Ilustración de Burgos, Revista de Ciencias, Letras y Artes, regaló a sus suscriptores fotografías de hombres ilustres y de monumentos de la ciudad. Desconocemos si lo hizo por el mismo procedimiento que $E l$ Genio o si se trató de fotografías que se entregaban en un álbum junto a cada ejemplar adquirido, pero sin insertarse en el texto.

En 1890 el periódico La Imparcialidad incluyó, por primera vez y de forma ocasional, un retrato de Eugenio Cemborain, consejero de Instrucción Pública del Estado, que visitó la ciudad. Es probable que el citado personaje aportara la placa de su foto y que fuera una práctica habitual en sus viajes.

En 1891 se editó El Anunciador, con motivo de las fiestas locales de San Pablo y San Pedro. Incluyó 12 fotografías de los principales edificios de Burgos. Se trató también de un catálogo o álbum con fotos, muy diferente a la inserción de imágenes fotográficas junto a los textos, como hizo El Genio:

Hemos recibido un bonito álbum fotográfico con las reseñas de las ferias y anuncios que los impresores B. Fernández y Compañía han tenido el buen acuerdo de publicitar. Contiene doce vistas fotográficas de Burgos, y es un adelanto que no podemos menos que aplaudir. Está bien fotografiado, bien impreso, bien encuadernado y es muy cómodo para llevarlo en el bolsillo. Y con todas estas condiciones no cuesta más que una peseta. ${ }^{5}$

Cabe resaltar que no fue hasta 1882, es decir, ocho años después que El Genio, cuando la Revista Médico Quirúrgica incluyó en su portada una fotografía pegada (Cuarterolo, 2009: 145). Por supuesto, ya a mediados del siglo XIX era común que algunos libros de Historia del Arte incluyeran láminas fotográficas, pero siempre como un recurso exquisito, dado el alto coste de aquellas reproducciones.

Esta técnica ha seguido usándose casi hasta nuestros días, combinando en los libros las páginas de tipografía con láminas de offset o huecograbado. Anecdóticamente, a

\footnotetext{
La Brújula fue un periódico político adscrito al Partido Liberal. Fundado en 1890, desapareció en 1891. En el número 46 del 20 de mayo de 1891, en su página 2 se incluyó la referencia a El Anunciador. Era muy común en la época que los periódicos dieran cuenta de la publicación de nuevas iniciativas periodísticas.
} 
pesar de los avances de la impresión digital hoy en día, es común encontrar libros de bajo presupuesto que insertan, normalmente en las últimas páginas, cuadernillos con ilustraciones a color para abaratar el precio. El Genio también recurrió a subterfugios para poder llamarse revista ilustrada, pero lo cierto es que por vez primera los lectores pudieron encontrar imágenes fotográficas de su ciudad en una publicación local, lo que sin duda supuso un cambio de paradigma en la visión de la realidad a través de la prensa.

\section{Conclusiones}

El Genio puede ser considerada como la primera publicación periódica de Burgos, y posiblemente de España, en insertar fotografías junto a los textos periodísticos. Supuso una innovación no exenta de ingenio y picaresca, ya que se ideó un método artesanal de pegado de cada imagen en la revista. Para poder hacerlo se diseñó un sistema de maquetación previo que dejaba en blanco los espacios en los que, una vez editada la revista, se pegaban las fotografías.

Aunque se especificaba "Láminas El Genio", lo cierto es que se ha podido comprobar que la imagen con la catedral de fondo corresponde al fotógrafo Laurent. La segunda imagen es de autoría desconocida, aunque no es descartable que perteneciera al mismo autor, al que se le compraban tantas imágenes fotográficas como ejemplares se editaban.

Es resaltable que se incluyera como director y editor a un joven adolescente, Juan Martínez Añibarro, hijo del que probablemente fue el verdadero creador de la revista, José Martínez Rives. Es probable que ello obedeciera a que el verdadero creador de este proyecto prefiriera no figurar por razones que se desconocen.

El Genio fue una publicación de lujo que elevó su precio con la inserción de las fotografías. Casi con toda seguridad esta circunstancia llevó al proyecto a la inviabilidad económica y por tanto a su cierre, ya que se aumentó el precio por ejemplar a una cantidad que era prohibitiva para la época.

La inserción de las fotografías en una publicación periódica, como fue El Genio, puede ser considerada como un antecedente, aún muy primitivo, del fotoperiodismo, que con el paso del tiempo se ha convertido en un elemento indispensable en las publicaciones periódicas.

La localización del único ejemplar de esta revista que se conserva ha permitido su puesta en valor y su restauración por parte del Archivo de la Diputación de Burgos. 


\section{Referencias bibliográficas}

Almuiña, C. (1997). La prensa vallisoletana durante el siglo XIX. Valladolid: Servicios de publicaciones de la Diputación provincial.

Cuarterolo, A. (2009). Fotografía y Teratología en América Latina. A Contra corriente, 7(1), 119-145. Recuperado de https://www.ncsu.edu/acontracorriente/ fall_09/articles/Cuarterolo.pdf

Chomón, J.M. (2017). Burgos: prensa y periodistas del siglo XIX. La importancia de la información local. Madrid: Editorial Fragua.

Francesc Valls, J. (1988). La prensa y la burguesía en el XIX español. Barcelona: Antrhopos.

Gómez Alonso, R. (2003). Comunicación y recepción de la imagen en la prensa decimonónica. El apoyo iconográfico en la prensa española del siglo XIX. Icono14, 1. doi: http://dx.doi.org/10.7195/ri14.v1i1.469

Hergueta, D. (1929). La imprenta en Burgos y su provincia. Burgos: Obra inédita.

López Mondéjar, P. (2005). Historia de la Fotografía en España. Barcelona: Lunwerg Editores.

Pantoja, A (2007). Prensa y fotografía. Historia del fotoperiodismo en España. El Srgonauta español, 4. Recuperado de http://argonauta.revues.org/1346

Pérez Salas, E. (2010). La revista científica y literaria: una propuesta editorial novedosa. Estudios. Revista de investigaciones literarias y culturales 18(36), 394415. Recuperado de http://132.248.9.34/hevila/EstudiosRevistadeinvestigacionesliterariasyculturales/2010/vol18/no36/7.pdf

Romero, A. (2012). Fotógrafos en la prensa aragonesa. Artigrama, 27, 153-173. Recuperado de https://www.unizar.es/artigrama/pdf/27/2monografico/07.pdf

Ruiz Velez, I. (2011). Profesores insignes del Instituto de Burgos. Burgos: Servicio de Publicaciones de la Diputación.

Saiz, M. D. (1999). Propaganda e imagen: los orígenes del fotoperiodismo. Historia y Comunicación Social, 4, 173-182. Recuperado de http://revistas.ucm.es/index. php/HICS/article/view/HICS9999110173A/19656

Tobar, M. L. (2009). José Martínez Rives, profesor, periodista y escritor "burgalés", autor de una tercera parte de Don Quijote. Boletín de la Institución Fernán González, 2, 337-384.

Wiessentehal, M. (1979). Historia de la Fotografía. Barcelona: Salvat.

Zaparaín, M. J. y Sainz, C. (2014). Visitas reales a Burgos (1808-1931). Burgos: Rico Adrados. 